\title{
Insights Into Excess Mortality During the First Months of the COVID-19 Pandemic From a Rural, Demographic Surveillance Site in Bangladesh
}

\author{
Syed Manzoor Ahmed Hanifi ${ }^{*}$, Sayed Saidul Alam, Sanjida Siddiqua Shuma and \\ Daniel D. Reidpath
}

Health Systems and Population Studies Division, icddr, b, Dhaka, Bangladesh

Background: Coronavirus disease 2019 (COVID-19) has spread globally, and the government of each affected country is publishing the number of deaths every day. This official figure is an underestimate as it excludes anybody who did not die in a hospital,

OPEN ACCESS

Edited by:

Zisis Kozlakidis,

International Agency for Research on

Cancer (IARC), France

Reviewed by:

Terri J. Harford,

Cleveland Clinic, United States

Md Shariful Islam,

North South University, Bangladesh

${ }^{*}$ Correspondence: Syed Manzoor Ahmed Hanifi hanifi@icddrb.org

Specialty section:

This article was submitted to Infectious Diseases - Surveillance, Prevention and Treatment, a section of the journal Frontiers in Public Health

Received: 29 October 2020 Accepted: 24 June 2021 Published: 29 July 2021

Citation:

Hanifi SMA, Alam SS, Shuma SS and Reidpath DD (2021) Insights Into Excess Mortality During the First Months of the COVID-19 Pandemic

From a Rural, Demographic Surveillance Site in Bangladesh.

Front. Public Health 9:622379. doi: 10.3389/fpubh.2021.622379 who did not test positive, who had a false result, or those who recovered on their own without a test.

Objective: This study aimed to measure the community level excess mortality using health and demographic surveillance in a rural area of Bangladesh.

Method: The study was conducted in Matlab, in a rural area of Bangladesh, with a Health and Demographic Surveillance System (HDSS) covering a population of 239,030 individuals living in 54,823 households in 142 villages. We examined the mortality in January-April from 2015 to 2020 and compared the mortality in 2020 with the historical trend of 2015-2019. Between 2015 and 2020, we followed 276,868 people until migration or death, whichever occurred first. We analyzed mortality using crude mortality rate ratio (MRR) and adjusted MRR (aMRR) from a Cox proportional hazard model. Mortality was analyzed according to age, sex, and period.

Results: During follow-up, 3,197 people died. The mortality rate per 1,000 person-years increased from 10 in 2019 to 12 in 2020 . Excess mortality was observed among the elderly population (aged 65 years and above). The elderly mortality rate per 1,000 person-years increased from 80 in 2019 to 110 in 2020, and the aMRR was 1.40 (95\% Cl: 1.19-1.64). Although an increasing tendency in mortality was observed between 2015 and 2019, it was statistically insignificant.

Conclusions: The study reported a $28 \%$ increase in excess deaths among the elderly population during the first months of the pandemic. This all-cause mortality estimation at the community level will urge policymakers, public health professionals, and researchers to further investigate the causes of death and the underlying reasons for excess deaths in the older age-group.

Keywords: COVID-19, mortality, Bangladesh, elderly, sex 


\section{INTRODUCTION}

Coronavirus disease 2019 (COVID-19), caused by severe acute respiratory syndrome coronavirus 2 (SARS-CoV-2) (1), first emerged in Wuhan city of Hubei province in China on December 31, 2020, when Chinese health officials informed the WHO about a cluster of 41 patients with mysterious pneumonia, supposedly connected to Huanan Seafood Wholesale Market (2). The detection time of the first cases varied from country to country; some counties detected early in the pandemic and some later. For instance, Bangladesh announced the first cases on March 8, 2020 (Table 1), and 2 days later on March 11, 2020, WHO declared COVID-19 as a pandemic (2).

The number of people migrating overseas from Bangladesh for employment annually is more than 400,000 (15). During the first months of 2020, more countries were placing lockdowns after the detection of the first cases of COVID-19 surfaced in each country. Bangladeshi migrant workers residing in these countries were compelled to return home to rural Bangladesh due to lack of income $(16,17)$. In addition, when Bangladesh announced its own lockdown on March 22, 2020 (18), after detecting the first three cases, an increasing number of people were leaving the capital city (19). Such movement of people opens the window for the spreading of the virus to more places in the country.

Official numbers of COVID-19 cases and deaths in Bangladesh are likely to be an underestimate of the real scenario because this mainly accounts for cases that have tested positive of coronavirus through laboratory confirmation (20) and deaths that are recorded in hospitals. What the numbers

TABLE 1 | Timeline of detection of first cases of COVID-19.

\begin{tabular}{|c|c|c|c|c|}
\hline \multirow[t]{2}{*}{ Country } & \multirow{2}{*}{$\frac{2019}{\text { December }}$} & \multicolumn{3}{|c|}{2020} \\
\hline & & January & February & March \\
\hline China $(3,4)$ & 31 & & & \\
\hline United Kingdom (5) & & 6 & & \\
\hline Thailand $(3,4)$ & & 13 & & \\
\hline Japan (4) & & 15 & & \\
\hline $\begin{array}{l}\text { Republic of Korea (South } \\
\text { Korea) (4) }\end{array}$ & & 20 & & \\
\hline United States (3) & & 20 & & \\
\hline France (6) & & 24 & & \\
\hline Germany (6) & & 27 & & \\
\hline India (7) & & 27 & & \\
\hline $\begin{array}{l}\text { United Arab Emirates (UAE) } \\
\text { (8) }\end{array}$ & & 29 & & \\
\hline Spain (9) & & 31 & & \\
\hline $\operatorname{Iran}(3,10)$ & & & 19 & \\
\hline Italy (3) & & & 21 & \\
\hline $\begin{array}{l}\text { Belarus, Lithuania, } \\
\text { Netherlands, New Zealand, } \\
\text { and Nigeria (11) }\end{array}$ & & & 27 & \\
\hline Saudi Arabia (12) & & & & 2 \\
\hline South Africa (13) & & & & 5 \\
\hline Bangladesh (14) & & & & 8 \\
\hline
\end{tabular}

have missed could be cases of deaths and infections before testing started, and the first cases were confirmed when only six PCR laboratories were available throughout the country (21). After the tests were made available, false test results could have eliminated any real cases and unaccounted for people who did not step forward for tests fearing isolation and stigma (22) or those that recovered from taking treatment at home (23). In addition, it is also difficult to determine the cause of death in many instances to find out whether the person was COVID-19 positive if they died prior to testing (24).

Weak civil and vital registration statistics (CVRS) for the great majority of low- and middle-income countries (LMIC) (25) means that we have remarkably little insight into the magnitude of the excess mortality associated with the COVID19 pandemic. This is in marked contrast to some high-income countries; for instance, during the first months of pandemic the United Kingdom published preliminary all-cause mortality data and COVID-19-related mortality data with a lag of only a few weeks unlike Bangladesh (26).

Although most countries are submitting daily data on the number of COVID-19 deaths to the WHO (27), without comparable all-cause mortality data, and all-cause mortality data for the equivalent time period over preceding years, it is difficult to estimate the excess mortality attributable to the pandemic. The excess mortality, of course, is not restricted to COVID-19 deaths alone; it also includes the non-COVID-19 deaths that arise from the loss of adequate care, as health systems become overstretched coping with COVID-19 cases.

Health and Demographic Surveillance System (HDSS) conducts surveillance of geographically prescribed populations for extended periods of time (28). They have, historically, provided estimates for many LMICs about the underlying birth, death, and fertility rates in the absence of an effective CVRS system (28). The Matlab HDSS is the longest running HDSS which has provided Bangladesh with some of its earliest data on rates of births and deaths (29). Utilizing these ongoing surveillance data, we are able to estimate the age and sex of mortality rates over the past 6 years and thereby to estimate the excess mortality in 2020 associated with the COVID-19 pandemic.

\section{MATERIALS AND METHODS Settings and Population}

The Matlab HDSS covers a population of 239,030 individuals living in 53,823 households in 142 villages in a rural district of Bangladesh that is situated $60 \mathrm{~km}$ south of Dhaka (30). All households are visited every 3 months to enquire about marriages, pregnancies, births, migrations, and deaths. Annually in the Matlab HDSS area, 5,298 babies are born, 1,687 people died, 2,671 people moved out of Bangladesh, and 1,371 people returned from abroad (30).

A web-based software application has been designed and developed for Matlab HDSS. Thirty-one tablets (smartphones) are connected to the mobile internet through the network of mobile operators. Traditionally, community health research workers (CHRWs) visit households every 3 months and record 
Total number of individuals

followed between January 1, 2015

and April 30, $2020 \mathrm{~N}=278290$

Males: $130,622(47 \%)$

Females: 147,668 (53\%)

Included in the analysis between

January 01, 2015 and April 30, 2020

$\mathrm{N}=276,868$

Males: $129,882(47 \%)$

Females: $146,986(53 \%)$

Age $<65$

$\mathrm{N}=255,633$

Males: $120,016(47 \%)$

Females: 135,617(53\%)

Elderly (65 years and above)

$\mathrm{N}=21,235$

Males: 9,866(46\%)

Females: 11,369(54\%)

\section{Died}

$\mathrm{N}=1,932(1,932 / 21,235=9 \%)$

Males: $958(958 / 21,235=10 \%)$

Females: $974(974 / 21,235=9 \%)$

Migration-out

$\mathrm{N}=2,796(2,796 / 21,235=13 \%)$

Males: $954(954 / 21,235=10 \%)$

Females: $1842(1842 / 21,235=16 \%)$

FIGURE 1 | Flowchart of the study population.

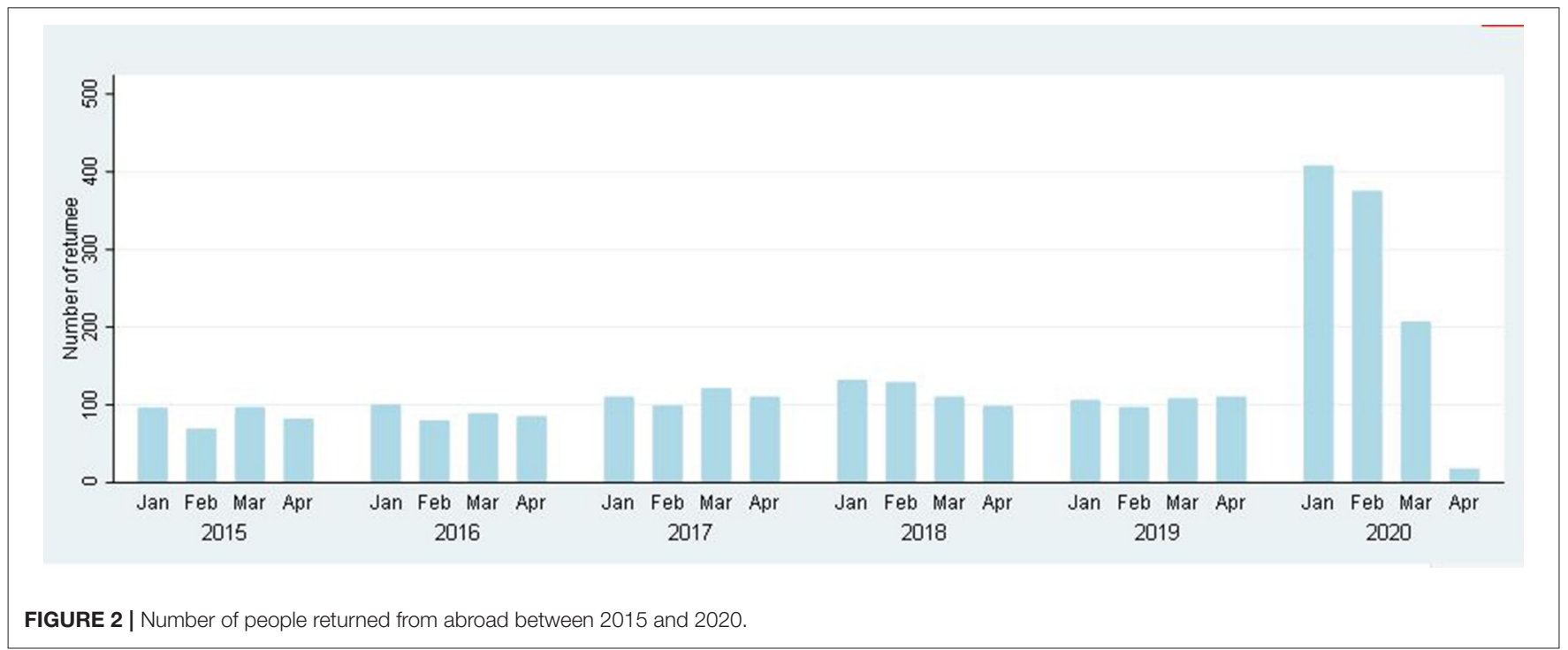


health and demographic events using these devices, and data are stored in the central database server. In the COVID-19 pandemic, to follow the precautionary guidelines in Bangladesh, CHRWs continued registering birth and death through mobile phones instead of household visits between March 25, 2020, and November 9, 2020. During data collection through mobile phones, CHRWs reached $85 \%$ of households in the first contact. Information of absent households (in the first contact) was updated in the next round.

\section{Epidemiological and Statistical Methods}

We analyzed mortality data in the study area between January 2020 and April 2020 to take into account the transmission of coronavirus, not only related to the movement of population from the capital city to rural areas after declaring the first lockdown on March 22, 2020, in Bangladesh but also the spread of the virus exacerbated by the migrants returning from abroad during the first months of the pandemic (January 2020April 2020) $(24,31)$. The mortality rate is compared with the mortality rates for the period of January 1 and April 30 in the years from 2015 to 2019. Between 2015 and 2020, we followed 278,290 people until migration or death, whichever occurred first (Figure 1). We calculated the mortality rate between January and April as seasonality in mortality was observed in the study area (30) (Figure 1). Deaths due to COVID-19 vary by age (32) and sex (33). We presented age-specific and sex-specific mortality and population size as the denominator. We used Cox proportional hazard models with age as the underlying timescale to estimate the aMRR. We included sex (33), period (30), and village (30) as potential confounders in the adjusted models.

\section{RESULTS}

\section{In-Migration}

In the Matlab HDSS area between January 2020 and April 2020, 1,008 people returned from abroad, which is 2.39 times (95\% CI: 2.29-2.55) higher than in 2019. Moreover, in 2020, in-migration was very high, which is 3.87 times higher (95\% CI: $3.10-4.14)$ in January and February compared to March and April (Figure 2).

\section{Mortality}

During the follow-up period from January to April from 2015 to 2020 , a total of 3,197 people died. In 2020, the number of people migrating back to Matlab from abroad was 406 in January, 375 in February, 207 in March, and 17 in April. From 2015 to 2019, the crude mortality rates (CMRs) per 1,000 person-years were 7.37 (95\% CI: 6.75-8.05), 7.63 (95\% CI: 7.01-8.31), 7.81 (95\% CI: 7.18-8.50), 8.98 (95\% CI: 8.29-9.73), and 9.70 (95\% CI: 8.9910.48), respectively. In 2020, the CMR was 11.61 (95\% CI: $10.51-$ 12.82) (Table 2). Figure 3 shows the age by year mortality rates. Between 2015 and 2019, there is little evidence of substantial yearto-year variation in the mortality rate in any age-group. In 2020, the mortality rate in the 65+ age-group (older adults) is markedly higher than in the previous 5 years.

The mortality rate in older adults per 1,000 person-years increased from 80 in 2019 to 110 in 2020, and the aMRR was 1.39 (95\% CI: 1.17-1.66) among older adults. The aMRR was

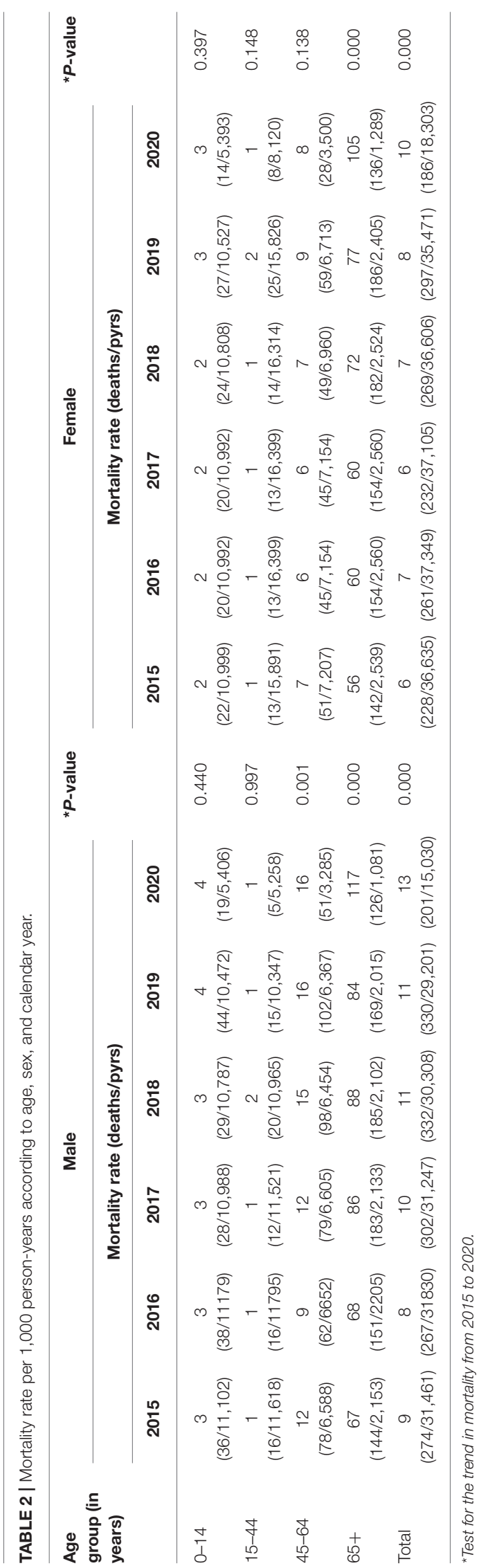




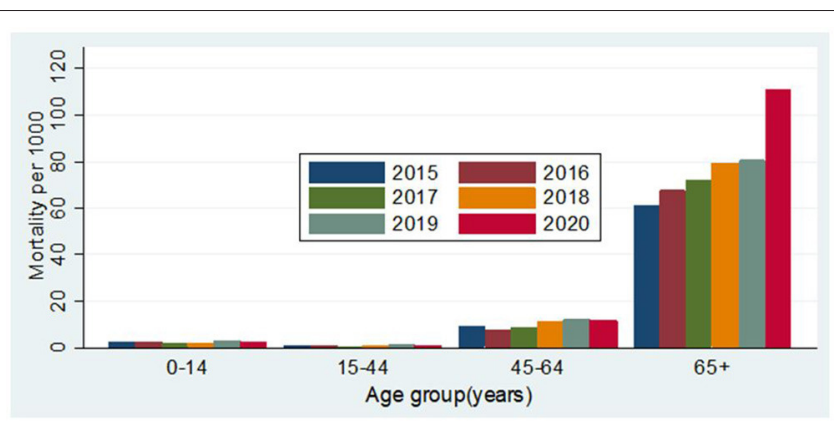

FIGURE 3 | Mortality per 1,000 person-years according to age and year.

1.38 (95\% CI: $1.09-1.75)$ for men and 1.43 (95\% CI: $1.16-1.77)$ for women. No significant difference was observed between men and women in increasing mortality from 2019 to 2020 ( $p=$ $0.910)$. It should be noted that the apparent increasing tendency in mortality observed in the 65+ age-group between 2015 and 2019 was not statistically significant (Table 1).

\section{DISCUSSION}

\section{Main Findings}

Compared to the five previous years, there is a clear, statistically significant difference in the mortality rate in the $65+$ age-group during the COVID-19 period in Matlab. This result is strong indication of a pandemic effect. No such difference was observed in any of the younger age-groups. The age by mortality effect is consistent with the global data on excess mortality that shows the highest mortality risk in those who are aged 65 years or older $(32,34,35)$.

\section{Interpretation}

The COVID-19 pandemic has had a significant negative impact on mortality rates in older people living in rural Bangladesh. It is not possible at this stage to determine the cause of deathalthough a verbal autopsy process, to be conducted in a few months, may give some insight into this. However, given the age effect in the excess mortality, the results strongly indicate either a direct or an indirect COVID-19 effect. The indirect effect may be attributable to a decreased likelihood of seeking life-saving care or a decreased capacity of the health system to manage non-COVID-19-related healthcare needs (36). For instance, the prevalence of hypertension is $53 \%$ among older age-groups (aged 65 years and above) in Bangladesh (37) and these hypertensive patients may not have been able to avail regular checkups or acquire medicines during the pandemic. Moreover, about $50 \%$ of deaths occur in the study area per year (30) due to conditions of chronic disease like heart disease and stroke. The pandemic situation may be responsible for deaths among such patients by preventing them from traveling the distance to a hospital that could provide them the immediate intensive care services that they required.

\section{Strength and Weakness}

We analyzed mortality from January to April, 2015-2020, which reduced any seasonality bias (30). Mortality rates were calculated using person-time techniques (38) that remain the basic epidemiological approach to estimating mortality, yet one of them is frequently missed in the calculation of mortality (39).

The data were only collected from one rural area, which may not reflect the situation in all rural Bangladesh. Indeed, Matlab appears to have better health outcomes than other rural areas of Bangladesh, and this may indicate that excess mortality rates would be worse elsewhere. The relatively short period of observation was to ensure the timely reporting of data.

We cited a number of news media-released reports as there was no detailed timeline information on these events during the first months of the pandemic.

\section{CONCLUSIONS}

Globally, the COVID-19 pandemic impacted the mortality of the overall population. COVID-19 pandemic attributed 30 deaths per 1,000 among the older age-group in the study area. We did not determine the deaths related to COVID-19 and non-COVID-19 causes. A further cause of death analysis will provide an estimate of excess deaths associated with COVID-19 and non-COVID-19 causes. It is important to examine whether the excess deaths as a result of access to healthcare and how the national COVID-19 policy operates on the decisions and actions of the people. Bangladesh needs to strengthen the CVRS system and national health statistics to monitor timely morbidity and mortality, especially in an epidemic or pandemic situation. Bangladesh should strive to strengthen its health systems by providing additional resources to make healthcare services more accessible to its residents irrespective of geographical locations.

\section{DATA AVAILABILITY STATEMENT}

The raw data supporting the conclusions of this article will be made available by the authors, without undue reservation.

\section{ETHICS STATEMENT}

The studies involving human participants were reviewed and approved by Ethical Review Committee of icddr,b. The patients/participants provided their written informed consent to participate in this study.

\section{AUTHOR CONTRIBUTIONS}

SH and DR conceived and designed the study and are the guarantors of the study. SA prepared the data file. SH analyzed the data and wrote the first draft of the manuscript. SS contributed to the literature review. All authors contributed to the final version of the manuscript. All authors had full access 
to all of the data (including statistical reports and tables) in the study and can take responsibility for the integrity of the data and the accuracy of the data analysis.

\section{FUNDING}

This research study was funded by core donors who provide unrestricted support to the icddr,b for its operations and research. icddr,b is grateful to the Government of Bangladesh, Canada,

\section{REFERENCES}

1. Yang X, Yu Y, Xu J, Shu H, Liu H, Wu Y, et al. Clinical course and outcomes of critically ill patients with SARS-CoV-2 pneumonia in Wuhan, China: a single-centered, retrospective, observational study. Lancet Respir Med. (2020) 8:475-81. doi: 10.1016/S2213-2600(20)30079-5

2. World Health Organisation. Coronavirus Disease (COVID-19) Outbreak.. Available online at: https://www.who.int/emergencies/diseases/novelcoronavirus-2019

3. Neilson S, Woodward A. A Comprehensive Timeline of the Coronavirus Pandemic at 1 Year, From China's First Case to the Present Online. (2020). Available online at: https://www.businessinsider.com/coronavirus-pandemictimeline-history-major-events-2020-3 (accessed December 25, 2020).

4. World Health Organisation. Novel Coronavirus (2019-nCoV). World Health Organization (2020).

5. Weaver M. Timeline of the UK's First Recorded Covid Cases Last Year Online: The Guardian. (2021). Available online at: https://www.theguardian.com/ world/2021/jan/26/timeline- of-the- uks-first-recorded-covid-cases-last-year (accessed January 26, 2021).

6. Germany's First Coronavirus Case Is Human-to-Human Transmission Online: Al-Jazeera. (2020). Available online at: https://www.aljazeera.com/news/2020/ 1/28/germanys-first-coronavirus-case-is-human-to-human-transmission (accessed January 28, 2020).

7. Andrews M, Areekal B, Rajesh K, Krishnan J, Suryakala R, Krishnan B, et al. First confirmed case of COVID-19 infection in India: a case report. Indian J Med Res. (2020) 151:490. doi: 10.4103/ijmr.IJMR_2131_20

8. Turak N. First Middle East Cases of Coronavirus Confirmed in the UAE Online: CNBC. (2020). Available online at: https://www.cnbc.com/2020/01/29/firstmiddle-east-cases-of-coronavirus-confirmed-in-the-uae.html (accessed January 29, 2020).

9. Timeline - How the Coronavirus Spread in Spain. Reuters (2020).

10. Taylor DB. A Timeline of the Coronavirus Pandemic. The New York Times (2021).

11. World Health Organisation. Coronavirus Disease 2019 (COVID-19). World Health Organisation (2020)

12. Saudi Arabia Announces First Case of Coronavirus. Arab News (2020).

13. Wiysonge CS. South Africa's War on COVID-19 Online: Think Global Health. (2020). Available online at: https://www.thinkglobalhealth.org/article/southafricas-war-covid-19 (accessed June 17, 2021).

14. Paul R. Bangladesh Confirms Its First Three Cases of Coronavirus. (2020). Available online at: https://www.reuters.com/article/us-health-coronavirusbangladesh-idUSKBN20V0FS (accessed March 8, 2020).

15. International Labour Organization. Labour Migration in Bangladesh Online: ILO. Available online at: https://www.ilo.org/dhaka/Areasofwork/labourmigration/lang--en/index.htm\#: :text=Each\%20year\%2C\%20more\%20than $\% 20400 \% 2$ C000,the $\% 20$ Bangladesh\%20for\%20overseas $\% 20$ employment (accessed June 21, 2020).

16. Mahmud J, Hasan R. Migrant Returning: Bangladeshs Sees a Huge Surge in Last Three Weeks Online (2020). Available online at: https://www.thedailystar. net/backpage/news/migrants-returning-bangladesh-sees-huge-surge-lastthree-weeks- 1960917 (accessed September 14, 2020).

17. International Organization for Migration. IOM Reports that 70 per cent of Returning Migrants to Bangladesh Struggle to Find Employment. (2020). Available online at: https://bangladesh.iom.int/news/iom-reports-70-cent-
Sweden, and the UK for providing core/unrestricted support.

\section{ACKNOWLEDGMENTS}

The authors are grateful to icddr,b for funding this study and the villagers for their cooperation in providing invaluable information. The untiring efforts of the team members of the Matlab HDSS in maintaining the surveillance system are gratefully acknowledged.

returning-migrants-bangladesh-struggle-find-employment\#: :text=Migrant \%20workers\%20are\%20particularly\%20vulnerable, social\%20services\%2C $\% 20$ healthcare $\% 20$ systems\%20and

18. Mamun S. Coronavirus: Bangladesh Declares Public Holiday From March 26 to April 4 (2020). Available online at: https://www.dhakatribune.com/ bangladesh/2020/03/23/govt-offices-to-remain-closed-till-april-4 (accessed March 23, 2020).

19. Lockdowns in Asia Have Sparked a Stampede Home Online: The Economist (2020) Available online at: https://www.economist.com/asia/2020/04/02/ lockdowns-in-asia-have-sparked-a-stampede-home (accessed April 4, 2020).

20. Ritchie H, Ortiz-Ospina E, Beltekian D, Mathieu E, Hasell J, Macdonald B, et al. Coronavirus Pandemic (COVID-19). Our World in Data [Internet]. (2020. Available online at: https://www.sipotra.it/wp-content/uploads/2020/ 03/Coronavirus-Disease-COVID-19-\%E2\%80\%93-Statistics-and-Research. pdf.

21. Islam A, Hassan H, Rahman T. Covid-19 Testing and Health Sector Resource Mobilisation. (2020). Available online at: https://www.thedailystar.net/ opinion/news/covid-19-testing-and-health-sector-resource-mobilisation1932293 (accessed July 18, 2020).

22. Sakib SN. Bangladesh: Low COVID-19 Testing Rate Raises Concerns Online. (2020). Available online at: https://www.aa.com.tr/en/asia-pacific/ bangladesh-low-covid-19-testing-rate-raises-concerns/1810132 (accessed April 04, 2020).

23. Maswood HM. COVID-19 Patients at Home Missing From DGHS Record in Bangladesh. (2020). Available online at: https://www.newagebd.net/ article/105305/covid-19-patients-at-home-missing-from-dghs-record-inbangladesh (accessed April 28, 2020).

24. Tracking Covid-19 Excess Deaths Across Countries. (2021). Available online at: https://www.economist.com/graphic-detail/coronavirus-excess-deathstracker (accessed May 11, 2021).

25. Appel D, Dahmm H. Civil Registration and Vital Statistics Benefit Health, Child Protection, and Governance: A Case Study on the Return on Investment for CRVS Systems 2018). Available online at: https://static1.squarespace. com/static/5b4f63e14eddec374f416232/t/5c06e14fc2241b2779ca96a9/ 1543954772402/CaseStudy_CRVS_Dec2018.pdf.

26. Coronavirus Pandemic (COVID-19). (2020). Available online at: https:// ourworldindata.org/coronavirus/country/bangladesh? country= BGD (accessed June, 2020).

27. World Health Organization. WHO Coronavirus Disease (COVID-19) Dashboard. (2020). Available online at: https://covid19.who.int/ (accessed June, 2020)

28. Ye Y, Wamukoya M, Ezeh A, Emina JB, Sankoh O. Health and demographic surveillance systems: a step towards full civil registration and vital statistics system in sub-Sahara Africa? BMC Public Health. (2012) 12:741. doi: 10.1186/1471-2458-12-741

29. Alam N, Ali T, Razzaque A, Rahman M, Zahirul Haq M, Saha SK, et al. Health and demographic surveillance system (HDSS) in Matlab, Bangladesh. Int J Epidemiol. (2017) 46:809-16. doi: 10.1093/ije/dyx076

30. Haq MZ, Haider MM, Mahmud K, Alam S, Saha SK, Barua S, et al. Registration of Health and Demographic Events 2017. Dhaka: icddr,b (2019).

31. Bangladesh Suspends All International Flights Except on 4 Routes. (2020). Available online at: https://www.thedailystar.net/country/bangladeshsuspends-all-international-flights-except-4-routes- 1883767 (accessed March 21, 2020). 
32. Dowd JB, Andriano L, Brazel DM, Rotondi V, Block P, Ding X, et al. Demographic science aids in understanding the spread and fatality rates of COVID-19. Proc Natl Acad Sci. (2020) 117:9696-8. doi: 10.1073/pnas.2004911117

33. Jin J-M, Bai P, He W, Wu F, Liu X-F, Han D-M, et al. Gender differences in patients with COVID-19: focus on severity and mortality. Front Public Health. (2020) 8:152. doi: 10.3389/fpubh.2020. 00152

34. Banerjee A, Pasea L, Harris S, Gonzalez-Izquierdo A, Torralbo A, Shallcross L, et al. Estimating excess 1-year mortality associated with the COVID-19 pandemic according to underlying conditions and age: a population-based cohort study. Lancet. (2020) 395:1715-25. doi: 10.1016/S0140-6736(20)30854-0

35. Nogueira PJ, de Araújo Nobre M, Nicola PJ, Furtado C, Carneiro AV. Excess mortality estimation during the COVID-19 pandemic: preliminary data from Portugal. Acta Médica Portuguesa. (2020) 33:376-83. doi: 10.20344/amp. 14316

36. Al-Zaman MS. Healthcare crisis in Bangladesh during the COVID-19 pandemic. Am J Trop Med Hyg. (2020) 103:1357-9. doi: 10.4269/ajtmh.20-0826

37. National Institute of population research and training (NIPORT), ICF. Bangladesh Demographic and Health Survey 2017-18. Dhaka and Rockville, MD: NIPORT and ICF (2020).
38. StataCorp L. Stata Survival Analysis and Epidemiological Tables Reference Manual. College Station, TX: StataCorp LP (1985).

39. Bhopal R. Covid-19 worldwide: we need precise data by age group and sex urgently. BMJ. (2020) 369:m1366. doi: 10.1136/bmj.m1366

Conflict of Interest: The authors declare that the research was conducted in the absence of any commercial or financial relationships that could be construed as a potential conflict of interest.

Publisher's Note: All claims expressed in this article are solely those of the authors and do not necessarily represent those of their affiliated organizations, or those of the publisher, the editors and the reviewers. Any product that may be evaluated in this article, or claim that may be made by its manufacturer, is not guaranteed or endorsed by the publisher.

Copyright (c) 2021 Hanifi, Alam, Shuma and Reidpath. This is an open-access article distributed under the terms of the Creative Commons Attribution License (CC BY). The use, distribution or reproduction in other forums is permitted, provided the original author(s) and the copyright owner(s) are credited and that the original publication in this journal is cited, in accordance with accepted academic practice. No use, distribution or reproduction is permitted which does not comply with these terms. 